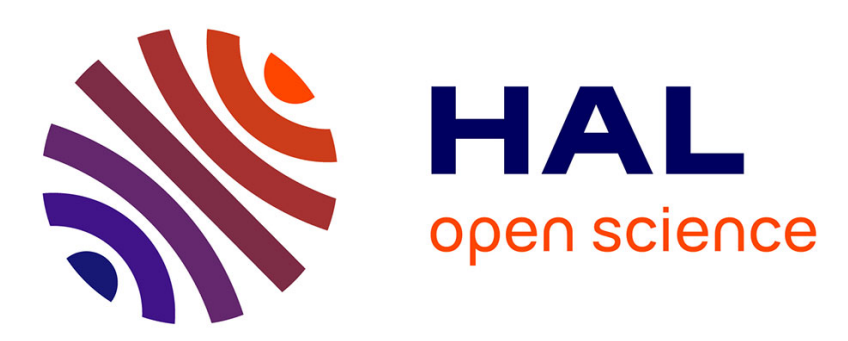

\title{
A criterion for determining the switching voltage of a metal-thin insulator-Si(n)-Si $(p+)$ device
}

\author{
J. Millán, F. Serra-Mestres, J. Buxó
}

\section{To cite this version:}

J. Millán, F. Serra-Mestres, J. Buxó. A criterion for determining the switching voltage of a metal-thin insulator-Si(n)-Si(p+) device. Revue de Physique Appliquée, 1979, 14 (11), pp.921-925. 10.1051/rphysap:019790014011092100 . jpa-00244680

\section{HAL Id: jpa-00244680 https://hal.science/jpa-00244680}

Submitted on 1 Jan 1979

HAL is a multi-disciplinary open access archive for the deposit and dissemination of scientific research documents, whether they are published or not. The documents may come from teaching and research institutions in France or abroad, or from public or private research centers.
L'archive ouverte pluridisciplinaire HAL, est destinée au dépôt et à la diffusion de documents scientifiques de niveau recherche, publiés ou non, émanant des établissements d'enseignement et de recherche français ou étrangers, des laboratoires publics ou privés. 


\title{
A criterion for determining the switching voltage of a metal-thin insulator-Si(n)-Si( $\left.\mathbf{p}^{+}\right)$device
}

\author{
J. Millán (*), F. Serra-Mestres $\left({ }^{*}\right)$ and J. Buxó $(* *)$ \\ (*) Departamento de Electricidad y Electrónica. Universidad Autónoma de Barcelona, Bellaterra, Barcelona, Spain \\ (**) Laboratoire d'Automatique et d'Analyse des Systèmes du C.N.R.S., 7, avenue du Colonel-Roche, 31400 Toulouse, France
}

(Reçu le 27 avril 1979, révisé le 24 juillet 1979, accepté le 26 juillet 1979)

\begin{abstract}
Résumé. - Les auteurs donnent un nouveau critère physique pour le phénomène de commutation des dispositifs du type M-I-S(n)-S( $\left.\mathrm{p}^{+}\right)$. Ce critère, basé sur la valeur de la capacité de la diode M-I-S(n), a pu être établi dans le cadre d'un modèle électrostatique particulièrement simple. Il a permis le calcul de la valeur de la tension de commutation ainsi que de sa dépendence en température. La valeur du courant à la commutation est aussi exprimée par des formules analytiques simples. Les valeurs obtenues sont en accord avec les résultats expérimentaux publiés.
\end{abstract}

\begin{abstract}
A new switching criterion for Metal-Insulator-Si(n)-Si( $\left.\mathrm{p}^{+}\right)$structures based on the MIS diode capacity is given within the framework of a simple electrostatic model. The values of the switching voltage and its dependence on temperature, together with the switching current are calculated on the basis of analytical expressions. These values are in accordance with experimental data.
\end{abstract}

1. Introduction. - There have been several recent reports on bistable switching properties of MetalInsulator-Si(n)-Si( $\mathrm{p}^{+}$) devices (MISS) [1-8].

J. Buxó et al. [9] have proposed a quantitative regenerative model that accounts for the switching properties of structures with a doping level of about $10^{15} \mathrm{~cm}^{-3}$ on $\mathrm{n}$-type silicon, in which the switching condition from the ON to the OFF state is assumed to be given by the onset of an inversion layer at the I-S interface.

In what follows, it is shown that the switching criterion based on the assumption of the occurrence of an inversion layer at the I-S interface should be modified.

Indeed, when the neutrality equation is stated in terms of the $F$ functions, it appears clearly that the obtained switching voltage value $V_{\mathrm{s}}$ is larger than that necessary to weakly invert the semiconductor surface for the first time.

As far as the current transport mechanism is concerned, a very simple model has been used which simply relates the majority and the minority carrier currents through the $\mathrm{p}^{+}-\mathrm{n}$ junction injection efficiency $\gamma$; thereby leading to a regenerative process between both currents [1]. These two currents are then supposed to tunnel across the insulator layer.
As a consequence, the new switching criterion proposed here is shown to correspond to an infinite value of the MIS capacitance.

Based upon this criterion, analytical expressions are determined for : the switching voltage $V_{\mathbf{s}}$, its temperature dependence $V_{\mathrm{s}}(T)$ and the switching current $I_{\mathrm{s}}$. A convenient agreement between these theoretical predictions and the experimental results [9] has been found.

2. The device model. - The equations governing the current transport across the insulator have been taken to be $[10,11]$ :

$$
\begin{aligned}
& j_{\mathrm{n}}=A^{*} T^{2} \mathrm{e}^{\left(-\chi_{\mathrm{cb}}^{1 / 2} \delta\right)} \exp \left(-\frac{E_{\mathrm{G}}}{2 k T}+u_{\mathrm{F}}\right) \times \\
& \times \mathrm{e}^{u_{\mathrm{s}}}\left[\mathrm{e}^{u_{\mathrm{A}}}-1\right] \\
& j_{\mathrm{p}}=A^{*} T^{2} \mathrm{e}^{\left(-\chi_{\mathrm{vb}}^{1 / 2} \delta\right)} \exp \left(-\frac{E_{\mathrm{G}}}{2 k T}-u_{\mathrm{F}}\right) \times \\
& \times \mathrm{e}^{\left(\xi_{s}-u_{B}\right)}\left[1-\mathrm{e}^{-\left(u_{A}+\xi_{B}\right)}\right]
\end{aligned}
$$

where $A^{*}$ is the Richardson constant, $\chi_{\mathrm{cb}}$ and $\chi_{\mathrm{vb}}$ the effective tunnel barriers for electrons and holes, respectively. In the former expressions, $\chi_{\mathrm{cb}}$ and $\chi_{\mathrm{vb}}$ 
should be expressed in $\mathrm{eV}$ and the thickness of the insulator $\delta$, in $\AA[10]$. The remaining parameters in (1) and (2) are defined in figure 1.

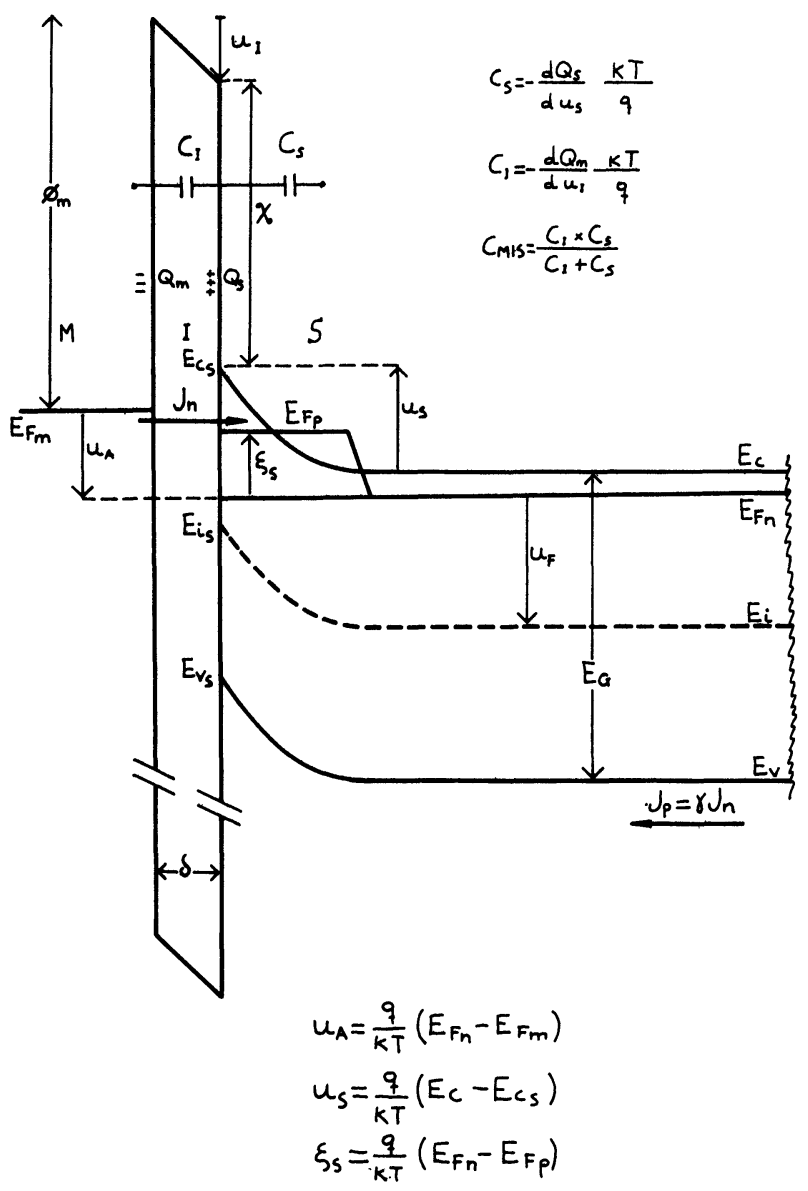

Fig. 1. - Energy diagram of the MIS diode.

The minority current $j_{\mathrm{p}}$ is related to the majority current $j_{\mathrm{n}}$ by

$$
j_{\mathrm{p}}=\gamma j_{\mathrm{n}} .
$$

In contrast with [9] we have chosen a more exact expression for the neutrality condition for the MIS diode,

$$
\frac{\varepsilon_{\mathrm{s}}}{L_{\mathrm{D}}} \frac{u_{\mathrm{s}}}{\left|u_{\mathrm{s}}\right|} F\left(u_{\mathrm{s}}, \xi_{\mathrm{s}}, u_{\mathrm{F}}\right)+\frac{\varepsilon_{\mathrm{I}}}{\delta} u_{\mathrm{I}}=0
$$

where $\varepsilon_{\mathrm{s}}$ and $\varepsilon_{\mathrm{I}}$ are the permittivities of the semiconductor and insulator, respectively, and $L_{\mathrm{D}}$ the semiconductor Debye length.

The value of $F\left(u_{s}, \xi_{s}, u_{F}\right)$ is [12] :

$$
\begin{aligned}
F\left(u_{\mathrm{s}}, \xi_{\mathrm{s}}, u_{\mathrm{F}}\right)=\left\{\mathrm{e}^{u_{\mathrm{F}}}\left[\mathrm{e}^{u_{\mathrm{s}}}-u_{\mathrm{s}}-1\right]+\right. \\
\\
\left.+\mathrm{e}^{-u_{\mathrm{F}}}\left[\mathrm{e}^{\left(\xi_{\mathrm{s}}-u_{\mathrm{s}}\right)}+u_{\mathrm{s}}-\mathrm{e}^{\xi_{\mathrm{s}}}\right]\right\}^{1 / 2}
\end{aligned}
$$

and the insulator voltage drop in units of $k T / q$ is,

$$
u_{\mathrm{I}}=\frac{q\left(\varphi_{\mathrm{m}}-\chi\right)-E_{\mathrm{G}} / 2}{k T}+u_{\mathrm{F}}+u_{\mathrm{s}}+u_{\mathrm{A}} .
$$

In order to simplify the model, the surface state charge has not been taken into account in the neutrality condition equation (4).

The set of equations (1) to (6) together with $j=j_{\mathrm{p}}+j_{\mathrm{n}}$ provide a link between $j$ and $u_{\mathrm{A}}$. Since the $\mathrm{p}^{+}-\mathrm{n}$ junction is forward-biased, its voltage drop will be neglected, so that $u_{\mathrm{A}}$ will stand for the normalized voltage applied to the structure.

In figure 2 the numerical solution of the aforementioned equations is represented. The $j\left(V_{\mathrm{A}}\right)$ characteristic shows up three different regions : the OFF region (1), the negative resistance region (2) and the ON region (3) in agreement with what has been experimentally observed $[1,2,6,7,9]$.

As already shown [13] the surface and bulk recombination currents will modify quantitatively the voltagecurrent characteristic but their amplitude has no impact in the physics of the bistable switching mechanism.

The inversion condition $\theta=2 u_{\mathrm{F}}+u_{\mathrm{s}}-\xi_{\mathrm{s}} \leqslant 0$ is plotted on figure 2 . It should be noted that the surface is inverted for $V_{\mathrm{A}}<V_{\mathrm{s}}\left(V_{\mathrm{A}}=k T / q u_{\mathrm{A}}\right)$; it is therefore clear that the inversion condition and the occurrence of switching correspond to two different physical situations.

3. The switching condition. - The device capacity $C_{\text {dev }}$, discounting the $\mathrm{p}^{+}-\mathrm{n}$ junction capacity, is given by :

$$
\frac{1}{C_{\mathrm{dev}}} \simeq \frac{1}{C_{\mathrm{MIS}}}=\frac{1}{C_{\mathrm{I}}}+\frac{1}{C_{\mathrm{s}}}
$$

where

$$
C_{\mathrm{s}}=-\frac{\mathrm{d} Q_{\mathrm{s}}}{\mathrm{d} u_{\mathrm{s}}} \frac{q}{k T}
$$

is the capacity per unit area on the surface of the n-type semiconductor and $Q_{s}$ its charge density, and

$$
C_{\mathrm{I}}=-\frac{\mathrm{d} Q_{\mathrm{m}}}{\mathrm{d} u_{\mathrm{I}}} \frac{q}{k T}=\frac{\varepsilon_{\mathrm{I}}}{\delta}
$$

is the insulator capacity per unit area, and $Q_{\mathrm{m}}$ the metal surface charge density.

The switching point on the curve $j\left(V_{\mathrm{A}}\right)$ (Fig. 2) corresponds to $\mathrm{d} u_{\mathrm{A}} / \mathrm{d} j=0$; i.e., the variation in the system current, $\mathrm{d} j$, gives rise to a change on the metal charge $\mathrm{d} Q_{\mathrm{m}}=-\mathrm{d} Q_{\mathrm{s}}$ which entails no variation in the applied voltage $\mathrm{d} u_{\mathrm{A}}=0$.

According to (6) the preceding condition may be written :

$$
\frac{\mathrm{d} Q_{\mathrm{m}}}{\mathrm{d} u_{\mathrm{I}}}=-\frac{\mathrm{d} Q_{\mathrm{s}}}{\mathrm{d} u_{\mathrm{s}}}
$$

which brings about :

$$
C_{\mathrm{I}}=-C_{\mathrm{s}}
$$




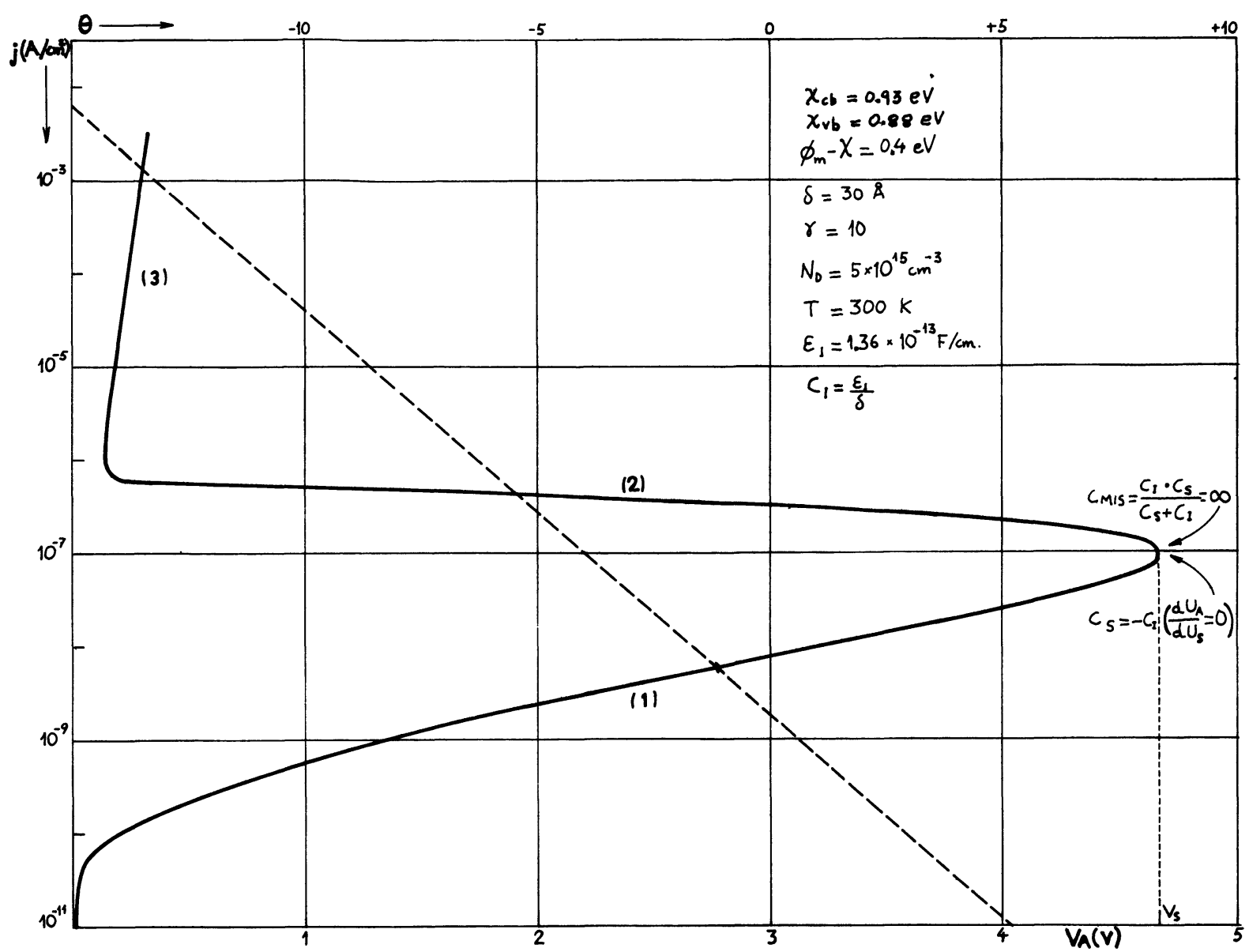

Fig. 2. - Numerical computation of the voltage-current characteristic for a typical device with the following parameters' values. $\left(\varphi_{\mathrm{m}}-\chi\right)=0.4 \mathrm{~V} ; \delta=30 \AA ; \gamma=10 ; N_{\mathrm{D}}=5 \times 10^{15} \mathrm{~cm}^{-3} ; T=300 \mathrm{~K} ; \varepsilon_{\mathrm{I}}=1.36 \times 10^{-13} \mathrm{~F} / \mathrm{cm}$. The dashed curve represents the inversion condition, $\theta$, against current.

by taking into account the neutrality of the charge :

and

$$
-\frac{\mathrm{d} Q_{\mathrm{s}}}{\mathrm{d} u_{\mathrm{s}}}=\frac{\mathrm{d} Q_{\mathrm{m}}}{\mathrm{d} u_{\mathrm{s}}}=\frac{\partial Q_{\mathrm{m}}}{\partial u_{\mathrm{s}}}+\frac{\partial Q_{\mathrm{m}}}{\partial u_{\mathrm{A}}} \frac{\mathrm{d} u_{\mathrm{A}}}{\mathrm{d} u_{\mathrm{s}}}
$$

$$
Q_{\mathrm{m}}=-\frac{k T}{q} \frac{\varepsilon_{\mathrm{I}}}{\delta} u_{\mathrm{I}}
$$

From (6), (9), (10), (12) and (13) it is then possible to deduce the following condition

$$
\frac{\mathrm{d} u_{\mathrm{A}}}{\mathrm{d} u_{\mathrm{s}}}=0
$$

In order to get the expression of the switching voltage the procedure is as follows.

It appears from (1), (2) and (3) that

$$
\mathrm{e}^{\xi_{s}}=\frac{A}{B} \mathrm{e}^{2 u_{s}}\left(\mathrm{e}^{u_{A}}-1\right)+\mathrm{e}^{-u_{A}}
$$

where

and

$$
A=(1+\gamma) A^{*} T^{2} \mathrm{e}^{\left(-E_{\mathrm{G}} / 2 k T\right)} \mathrm{e}^{\left(-\chi_{\mathrm{cb}}^{1 / 2} \delta\right)} \mathrm{e}^{u_{F}}
$$

$$
B=\frac{1+\gamma}{\gamma} A^{*} T^{2} \mathrm{e}^{\left(-E_{G} / 2 k T\right)} \mathrm{e}^{\left(-x_{\mathrm{c} v}^{1 / 2} \delta\right)} \mathrm{e}^{-u_{F}} .
$$

Substituting the value of $\xi_{s}$ in (4) and taking into account that for values close to those of the switching voltage $u_{\mathrm{A}} \gg 1, u_{\mathrm{s}}<0$ and $\left|u_{\mathrm{s}}\right| \gg 1$, it may be written

$$
\begin{aligned}
& D\left(u_{\mathrm{A}}+u_{\mathrm{s}}+C\right)- \\
& \quad-\left\{-u_{\mathrm{s}} \mathrm{e}^{u_{\mathrm{F}}}+\mathrm{e}^{-u_{\mathrm{F}}}\left[\frac{A}{B} \mathrm{e}^{\left(u_{\mathrm{s}}+u_{\mathrm{A}}\right)}\right]\right\}^{1 / 2}=0
\end{aligned}
$$

where

$$
D=\frac{\varepsilon_{\mathrm{I}}}{\varepsilon_{\mathrm{s}}} \frac{L_{\mathrm{D}}}{\delta}
$$

and

$$
C=\frac{q\left(\varphi_{\mathrm{m}}-\chi\right)-E_{\mathrm{G}} / 2}{k T}+u_{\mathrm{F}} .
$$

From (14) and (18) it appears that the values of $u_{\mathrm{s}}+u_{\mathrm{A}}$ at the switching point are restricted by the following transcendental equation :

$$
\begin{aligned}
\mathrm{e}^{\left(u_{\mathrm{s}}+u_{\mathrm{A}}\right)}-2 \frac{B}{A} D^{2} \mathrm{e}^{u_{\mathrm{F}}}\left(u_{\mathrm{s}}+u_{\mathrm{A}}\right)- \\
\quad-\frac{B}{A}\left(\mathrm{e}^{2 u_{\mathrm{F}}}+2 D^{2} C \mathrm{e}^{u_{\mathrm{F}}}\right)=0 .
\end{aligned}
$$


Neglecting the linear term in (21) the error $\varepsilon$ produced in $u_{\mathrm{s}}+u_{\mathrm{A}}$ is

$$
|\varepsilon|=\frac{2 D^{2}}{\mathrm{e}^{u_{\mathrm{F}}}+2 D^{2}(C-1)} \ll 1
$$

for values in the order of magnitude of those in figure 2 and neglecting the less significant terms the following expression for the switching voltage $V_{\mathrm{s}}$ is obtained :

$$
\begin{aligned}
V_{\mathrm{s}}= & -\left(\varphi_{\mathrm{m}}-\chi\right)+\frac{k T}{q} \ln \frac{\sqrt{N_{\mathrm{c}} N_{\mathrm{v}}}}{N_{\mathrm{D}}} \\
& +\frac{\varepsilon_{\mathrm{I}}^{2}}{2 q \varepsilon_{\mathrm{s}} \delta^{2} N_{\mathrm{D}}}\left[\varphi_{\mathrm{m}}-\chi-\frac{k T}{q} \ln \frac{\gamma \sqrt{N_{\mathrm{c}} N_{\mathrm{v}}}}{\xi N_{\mathrm{D}}}\right]^{2} \\
& +\frac{k T}{q}\left(1-\frac{\varepsilon_{\mathrm{I}}^{2}}{q \varepsilon_{\mathrm{s}} \delta^{2} N_{\mathrm{D}}}\right)
\end{aligned}
$$

$$
\times\left[\varphi_{\mathrm{m}}-\chi-\frac{k T}{q} \ln \frac{\gamma \sqrt{N_{\mathrm{c}} N_{\mathrm{v}}}}{\xi N_{\mathrm{D}}}\right]
$$

where

$$
\begin{aligned}
\xi=\mathrm{e}^{\left[\left(x \delta^{1} \mathrm{~g}^{2}-x^{1} 6^{2}\right) \delta\right]} \times & \\
\times & {\left[1+\frac{\varepsilon_{\mathrm{I}}^{2}}{q \varepsilon_{\mathrm{s}} \delta^{2} N_{\mathrm{D}}}\left(\varphi_{\mathrm{m}}-\chi-\frac{k T}{q} \ln \frac{\sqrt{N_{\mathrm{c}} N_{\mathrm{v}}}}{N_{\mathrm{D}}}\right)\right] }
\end{aligned}
$$

and where $N_{\mathrm{c}}$ and $N_{\mathrm{v}}$ are the effective density of states in the conduction and valence bands, respectively; $N_{\mathrm{D}}$ is the doping level of the semiconductor. It should be noted that equation (22) is valid for values of $\varphi_{\mathrm{m}}-\chi$ such that the semiconductor surface is depleted for $u_{\mathrm{A}}=0$.

It can, then, be shown that the current density $j_{\mathrm{s}}$ at the switching point is given by :

$$
j_{\mathrm{s}}=A^{*} T^{2} \mathrm{e}^{\left(-\chi \mathrm{d}\left(\mathrm{s}^{2} \delta\right)\right.}\left[\frac{N_{\mathrm{D}}}{\sqrt{N_{\mathrm{c}} N_{\mathrm{v}}}}+\frac{\varepsilon_{\mathrm{I}}^{2}}{q \varepsilon_{\mathrm{s}} \delta^{2} \sqrt{N_{\mathrm{c}} N_{\mathrm{v}}}}\left(\varphi_{\mathrm{m}}-\chi+\frac{k T}{q} \ln \frac{N_{\mathrm{D}}}{\sqrt{N_{\mathrm{c}} N_{\mathrm{v}}}}\right)\right]
$$

and that a convenient approximation for the temperature coefficient of the switching voltage is :

$$
\frac{\mathrm{d} V_{\mathrm{s}}}{\mathrm{d} T}=-\frac{\varepsilon_{\mathrm{I}} \sqrt{2 V_{\mathrm{s}}}}{T \delta \sqrt{q \varepsilon_{\mathrm{s}} N_{\mathrm{D}}}}\left[\left(\varphi_{\mathrm{m}}-\chi\right)(1+1 / C)+\frac{3}{2} \frac{k T}{q C}-\frac{\delta \sqrt{2 V_{\mathrm{s}} q \varepsilon_{\mathrm{s}} N_{\mathrm{D}}}}{\varepsilon_{\mathrm{I}}}+\frac{k T}{2 q}\right]
$$

where only the second term in (22) has been considered, and $\gamma$ is taken to be independent of temperature.

The numerical application has been carried out by using the values in figure 2 ; at this stage it should be pointed out that the best fit has been obtained by assuming that the value of the thin insulator permit-

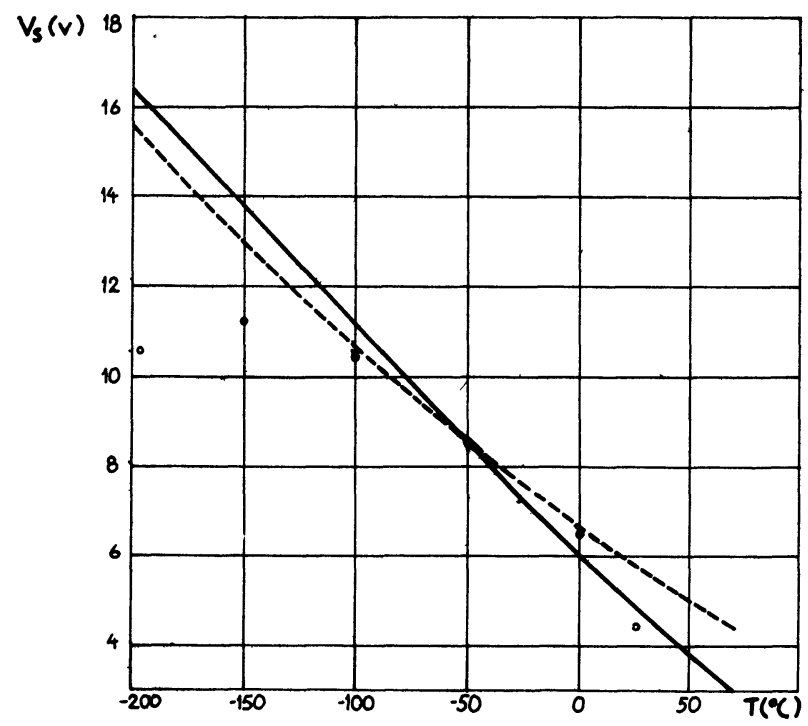

Fig. 3. - The switching voltage against temperature according to $(22)$ is here represented by the continuous line, and (26) by the dashed line, for the same parameters' values as in figure 2 ; $\circ$ are the experimental data from [9]. tivity is lower than for the bulk material [14]. The values of $V_{\mathrm{s}}$ along with its temperature dependence have been plotted on figure 3 where a comparison is also made with the corresponding experimental data obtained by J. Buxó et al. [9].

If the barrier involved is sufficiently high $(C>1)$, the integration of (25) leads to

$$
\begin{aligned}
V_{\mathrm{s}}(T)=\left[\frac{\varepsilon_{\mathrm{I}}}{\delta \sqrt{2 q \varepsilon_{\mathrm{s}} N_{\mathrm{D}}}}\left(\varphi_{\mathrm{m}}-\chi\right) \times\right. \\
\left.\quad \times\left(1-\frac{T}{T_{0}}\right)+\frac{T}{T_{0}} \sqrt{V_{\mathrm{s}}^{0}}\right]^{2}
\end{aligned}
$$

where $V_{\mathrm{s}}^{0}$ is the switching voltage for $T=T_{0}$. Figure 3 also plots the values of $V_{s}(T)$ given by (26). It should be noted that the discrepancy with the preceding numerical values is below $10 \%$ for temperatures up to $-100^{\circ} \mathrm{C}$. However, in the temperature range between $-100^{\circ} \mathrm{C}$ and $-200^{\circ} \mathrm{C}$, a greater discrepancy is found due probably to the surface currents which has been neglected in this model.

4. Conclusion. - A general switching criterion based on the MIS diode capacity value for MetalInsulator-Si(n)-Si $\left(\mathrm{p}^{+}\right)$structures has been proposed within the framework of a simple electrostatic model. The main features of the switching mechanism can then be accounted for. The values obtained from the 
analytical expressions of both the switching voltage and its temperature dependence up to $-100^{\circ} \mathrm{C}$, as well as that of the switching current agree well with the experimental data obtained for Silicon doping levels of the order of $10^{15} \mathrm{~cm}^{-3}$.

The preceding investigation of the features of the capacitance of the MISS devices as a function of current and voltage will be extended to cover the two remaining zones of the $I(V)$ curves, i.e., the negative resistance and the $\mathrm{ON}$ state. The impact of the semiconductor doping level on capacitance properties will also be discussed in detail.

\section{References}

[1] Yamamoto, T. and Morimoto, H., Appl. Phys. Lett. 20 (1972) 269.

[2] KROGER, H. and Wegener, H. A. R., ibid. 23 (1973) 397.

[3] Kroger, H. and Wegener, H. A. R., ibid 27 (1975) 303.

[4] Yamamoto, T., Kawamura, K. and Shimigu, H., Solid-State Electron. 19 (1976) 701.

[5] Simmons, J. G. and El-Badry, A., ibid 20 (1977) 955.

[6] El-Badry, A. and Simmons, J. G., ibid 20 (1977) 963.

[7] KROGER, H. and Wegener, H. A. R., ibid 21 (1977) 643.

[8] Kroger, H. and Wegener, H. A. R., ibid 21 (1977) 655.
[9] Buxó, J., Owen, A. E., Sarrabayrouse, G. and Sebaci, J. P., Revue Phys. Appl. 13 (1978) 767.

[10] CARd, H. C. and RHOderick, E. H., J. Phys. D 4 (1971) 1589.

[11] Buxó, J., Esteve, D. and Sarrabayrouse, G., Phys. Status Solidi (a) 37 (1976) K-105.

[12] Sze, S. M., Physics of semiconductor devices (J. Wiley, New York) 1969.

[13] Sarrabayrouse, G., These d'Etat (Sciences). Université Paul-Sabatier de Toulouse (1978).

[14] BIREY, H., J. Appl. Phys. 48 (1977) 5209. 